\title{
Extracorporeal transient distal penile corporoglanular shunt in early ischemic priapism treatment
}

\author{
Onder Canguven ${ }^{1,2}$, Raidh A. Talib² \\ ${ }^{1}$ Kartal Teaching and Research Hospital, Istanbul, Turkey; ${ }^{2}$ Hamad General Hospital, Doha, Qatar
}

\begin{abstract}
Purpose: Ischemic priapism, which is a compartment syndrome, needs urgent treatment in order to nourish corpora cavernosa. As the first step, the aspiration of blood and/or the irrigation of the cavernosal bodies are performed to prevent fibrotic activity and secure erectile capability. While performing aspiration and irrigation, there are some risks of the procedure in which most refrained one is cardiovascular side effects of adrenergic agonists. We aimed to evaluate extracorporeal transient distal penile corporoglanular shunt technique in place of aspiration/ irrigation techniques for early ischemic priapism treatment. Materials and Methods: In this transient shunt technique, a sterile closed system blood collection set (BD Vacutainer, Cat. No.: 367282; NJ, USA), which has two $21 \mathrm{G}$ needles, was used. The length of the needle and tubing was $19 \mathrm{~mm}$. (0.75 inch) and $178 \mathrm{~mm}$. (7 inches), respectively. This blood collection set was designed to be used not only for blood collection but can also be used for short term infusions (maximum 2 hours).

Results: Ten patients out of fifteen with early ischemic priapism were successfully treated with this transient shunt technique. The permanent detumescence achieved in the first 10 minutes in nine out of fifteen patients. No additional procedure needed after the disappearance of rigidity in successfully treated patients. The permanent detumescence achieved in the first $10 \mathrm{~min}-$ utes in nine out of fifteen patients.

Conclusions: We demonstrated that this extracorporeal transient shunt technique gets some advantages over aspiration and irrigation in early ischemic priapism treatment. Our results indicate that the presented technique to be offered for the patients with an ischemic priapism episode of no more than 7 hours.
\end{abstract}

\section{ARTICLE INFO}

Available at:

www.brazjurol.com.br/videos/september_october_2014/Canguven_710_711video.htm

Int Braz J Urol. 2014; 40 (Video \#14): 710-711

Submitted for publication:

August 04, 2014

Accepted after revision:

October 20, 2014
Correspondence address:

Onder Canguven, MD

Hamad General Hospital

Department of Urology Andrology Clinic 3050 Doha, Qatar

Telephone:+ 974 443-91864

E-mail: ocanguven@yahoo.com 


\section{EDITORIAL COMIMENT}

This video demonstrates a novel technique that can be used in the armamentarium of urologists in the treatment of priapism. This is a minimally-invasive distal shunt that can resolve pria-

\section{REFERENCES}

1. Winter CC. Cure of idiopathic priapism: new procedure for creating fistula between glans penis and corpora cavernosa. Urology. 1976;8:389-91. pism with less blood-loss and permanent scarring than Winter (1) or Ebbehoj (2) shunts. A potential obstacle to the widespread adoption of this technique may be the availability of the specialized needle set. However, the authors should be commended for their innovation.
2. Ebbehoj J. A new operation for priapism. Scand J Plast Reconstr Surg. 1974;8:241-2.

Rafael E. Carrion, MD \&

Chriostopher Yang, MD Director of Research

Residency Program Director Department of Urology USF Health, College of Medicine E-mail: rcarrion@health.usf.edu 